\title{
High Blood Pressure in External Consultation in Cardiology of Kati
}

\author{
Ichaka Menta1 , Hamidou Oumar Ba1, Souleymane Coulibaly², Ibrahima Sangare', \\ Djénébou Traore ${ }^{3}$, Coumba Thiam4 ${ }^{4}$, Yacouba Fofana ${ }^{4}$, Ilo Bella Diall2 ${ }^{2}$, Youssouf Camara ${ }^{4}$, \\ Samba Sidibe ${ }^{2}$, Mamadou Diakite ${ }^{2}$, Massama Konate ${ }^{3}$, Kassoum Mamourou Sanogo' \\ ${ }^{1}$ Cardiology Service of Gabriel Touré University Hospital Center (CHU Gabriel Touré), Bamako, Mali \\ ${ }^{2}$ Cardiology Service of Point G University Hospital Center (CHU Point G), Bamako, Mali \\ ${ }^{3}$ Internal Medicine Service of Point G University Hospital Center (CHU Point G), Bamako, Mali \\ ${ }^{4}$ Cardiology Service of Kati University Hospital Center (CHU Kati), Kati, Mali \\ Email: mentasomonosso@yahoo.fr
}

How to cite this paper: Menta, I., Ba, H.O., Coulibaly, S., Sangare, I., Traore, D., Thiam, C., Fofana, Y., Diall, I.B., Camara, Y., Sidibe, S., Diakite, M., Konate, M. and Sanogo, K.M. (2018) High Blood Pressure in External Consultation in Cardiology of Kati. World Journal of Cardiovascular Diseases, 8, 533-538. https://doi.org/10.4236/wjcd.2018.812052

Received: November 13, 2018

Accepted: December 17, 2018

Published: December 20, 2018

Copyright $\odot 2018$ by authors and Scientific Research Publishing Inc. This work is licensed under the Creative Commons Attribution International License (CC BY 4.0).

http://creativecommons.org/licenses/by/4.0/ (c) (i) Open Access

\begin{abstract}
Objective: To study hypertension and its manifestations in Out-patients' Department of Cardiology of Kati. Methods: The study was traversal and it was based on a sample of 300 patients, reached during the interval of 12 (twelve) months (from June 2012 to June 2013). Results: The predominance was among the females with $68.7 \%$. The average age was about $55.8 \pm 12.2$ years old. The extreme ages were about 21 and 90 years old. In the set, $66 \%$ of the patients lived in the town of Kati. The symptoms of Dieulafoy were predominantly the reasons for consultation with $55.7 \%$. The cardiac frequency in the vast majority of cases was normal $(85.3 \%)$. The left ventricular hypertrophy in the electrocardiogram was observed in more than half of the cases, that is to say, $51.3 \%$. In a bit higher proportion, the echocardiography Doppler became normal, that is to say, $54 \%$. Brain scanner done on 9 patients found out signs of cerebrovascular stroke in 8 patients, that is to say, a frequency of $88.9 \%$. In $76 \%$ of cases of orthostatic hypotension, the patients were hypertensive. The blood pressure was normal during the passage of orthostatism in the cases of 258 of our patients, that is to say, $86.0 \%$ of the cases. However, the orthostatic hypotension $(\mathrm{OH})$ was observed in the cases of 42 patients, that is to say, $14.0 \%$ of the cases. In this set of patients, $41.6 \%$ of the moans were due to cephalgias and dizziness's. The monotherapy of patients with $\mathrm{OH}$ represented $47.6 \%$ of the cases. Blood pressure was not controlled in $66.7 \%$ of the cases of $\mathrm{OH}$. The biological examinations required were normal in $52.4 \%$ of the cases. Conclusion: The hypertension is a disease which is frequently the reason for consultation in cardiology. The symptoms of Dieulafoy can be the signs of call. The complications are sometimes recurrent. The orthostatic hypotension should be found out even under monotherapy on a balanced or non-balanced hypertensive patient through treatment.
\end{abstract}




\section{Keywords}

High Blood Pressure, Out-Patients' Department, Cardiology, Kati

\section{Introduction}

The problem of hypertension and its complications, mainly the strokes, heart or kidney failure, the acute coronary syndrome, are well known. The treatment of HTA has clearly demonstrated its ability to protect patients from complications, including now at an advanced age, beyond 80 years. The diagnosis of HTA and its follow-up are based on the PA measured in the seated or lying position. The measurement of PA in standing position is strongly recommended, especially in the elderly, but in practice is only too seldom carried out. Yet, orthostatic hypotension is an eventuality: frequent, sometimes misleading and always serious. The recommendations of learned societies underline the insufficient control of hypertensive patients under treatment. At the cardiology service of the hospital of Kati, the rate of the observance of the antihypertensive treatment was about $31.63 \%$ in 2012.

\section{Methods}

It was a transversal study based on a sample of 300 patients, reached during the interval of 12 (twelve) months (from June, $1^{\text {st }} 2012$ to June, $1^{\text {st }} 2013$ ). The study was systematically based on all the hypertensive patients received in cardiology consultations abiding by the inclusion criteria, that is to say 300 patients.

Were included in the study all the hypertensive patients regularly followed in our service under treatment at least since one month and correctly following the treatment.

Hypertension isdefined as office SBP values $\geq 140 \mathrm{~mm} \cdot \mathrm{Hg}$ and/or diastolic BP (DBP) values $\geq 90 \mathrm{~mm} \cdot \mathrm{Hg}$.

Each patient benefited from an individual survey record. This survey record was filled in the day of the study, that is to say one month or more of follow-up.

The confidentiality of the names of patients was respected.

The investigation was conducted during the different appointments with patients, that is to say one month or more under treatment and correctly following the treatment.

The processing and statistical analyses of the data were done through the softwares SPSS (version 12) and Microsoft Word 2007.

\section{Results}

The female sex predominated with $68.7 \%$ of the cases (Table 1 ). The average age was about 55.8 years old \pm 12.2 years old; with extreme ages of 21 years old and 90 years old. In the set $66 \%$ of the patients lived in the town of Kati (Table 2). 
Table 1. Distribution of patients by sex.

\begin{tabular}{ccc}
\hline Sex & Frequency & Percentage (\%) \\
\hline Female & 206 & $68.7 \%$ \\
Male & 94 & $31.3 \%$ \\
Total & 300 & $100 \%$ \\
\hline
\end{tabular}

Table 2. Distribution of patients by residence.

\begin{tabular}{ccc}
\hline Residence & Frequency & Percentage (\%) \\
\hline Urban & 198 & $66.0 \%$ \\
Peri-Urban & 48 & $16.0 \%$ \\
Other & 54 & $18.0 \%$ \\
Total & 300 & $100 \%$ \\
\hline
\end{tabular}

The symptoms of Dieulafoy represented the most frequent reasons for consultation, that is to say $55.7 \%$ of the cases (Table 3 ). The cardiac frequency was normal in $85.3 \%$ of cases (Table 4). The left ventricular hypertrophy (LVH) was the most represented anomaly with $51.3 \%$ of the cases in the electrocardiogram (Table 5). The echocardiography Dopplerwas on 126 of our patients (Table 6), and it was normal in 68 patients, that is to say $54 \%$ of the cases. The cerebral tododensitometry was done on 9 of our patients (Table 7), and has objectivized an ischaemic CVA in 8 patients that is to say $88.9 \%$ of the cases. Blood pressure was controlled in $68.7 \%$ of the cases in the overall population of patients (Table 8). High blood pressure was the most frequent with $76 \%$ of the cases among the patients with orthostatic hypotension. Blood pressure was normal during the passage of orthostatism in 258 of our patients that is to say $86.0 \%$ of the cases; however, orthostatic hypotension $(\mathrm{OH})$ was observed in 42 patients that is to say $14.0 \%$ of the cases. In this set $41.6 \%$ of the moans were due to cephalgias and dizzinesses. Blood pressure was not controlled in $66.7 \%$ of the cases of $\mathrm{OH}$. The biological examinations required were normal in $52.4 \%$ of the cases. Themonotherapy of patients with $\mathrm{OH}$ represented $47.6 \%$ of the cases.

\section{Discussion}

In the series the predominance was female with $68.7 \%$. This could be due to, beside to the other factors of cardiovascular risks, the effect of menopause on women because of the advanced average age of our patients. Such average age was $55.8 \pm 12.2$ years old with extreme ages of 21 years old and 90 years old, highlighting that age is a non-modifiable factor of cardiovascular risk for men as well as women as in consistence with the literature [1] [2]. Patients came from different horizons with a neat predominance of the town of Kati (66.0\%) in relationship with the geographical location of the Kati hospital where the investigation was carried out. The symptoms of Dieulafoy were the most frequent reasons for consultation with $55.7 \%$. This high rate would be linked to high blood pressure. These symptoms were very often frequent during hypertension although 
Table 3. Distribution of patients according to the reasons for consultation.

\begin{tabular}{ccc}
\hline Pattern & Frequency & Percentage (\%) \\
\hline Sign of Dieulafoy & 167 & $55.7 \%$ \\
HBP & 70 & $24 \%$ \\
Chest pain & 25 & $8.3 \%$ \\
Heart Failure & 18 & $6 \%$ \\
Arrhytmia & 10 & $3 \%$ \\
Cardiomegaly & 10 & $3 \%$ \\
Total & 300 & $100 \%$ \\
\hline
\end{tabular}

Table 4. Distribution of patients by heart rate.

\begin{tabular}{ccc}
\hline Heart Rate & Patients & Percentage (\%) \\
\hline Normal & 256 & $85.3 \%$ \\
Fast & 38 & $12.7 \%$ \\
Slow & 6 & $2.0 \%$ \\
Total & 300 & $100 \%$ \\
\hline
\end{tabular}

Table 5. Distribution of patients according to the electrocardiographic abnormalities.

\begin{tabular}{ccc}
\hline Electrocardiographic abnormalities & Frequency & Percentage (\%) \\
\hline LVH & 154 & $51.3 \%$ \\
LVH + LEFT ATRIAL HYPERTROPHY & 1 & $0.4 \%$ \\
Excitement disorder & 7 & $2.3 \%$ \\
Conduction disorder & 17 & $5.7 \%$ \\
Supraventricular rhythm disorder & 3 & $1.0 \%$ \\
QS aspect & 4 & $1.3 \%$ \\
R wave progression delay & 10 & $3.3 \%$ \\
Repolarization disorder & 16 & $5.3 \%$ \\
Regular sinus rhythm without pathology & 88 & $29.4 \%$ \\
Total & 300 & $100 \%$ \\
\hline
\end{tabular}

Table 6. Distribution of patients according to the echocardiographic results.

\begin{tabular}{ccc}
\hline Echocardiography & Frequency & Percentage (\%) \\
\hline Normal & 68 & $22.7 \%$ \\
Relaxation disorder & 18 & $6.0 \%$ \\
Diseases & 40 & $13.3 \%$ \\
Not done & 174 & 58.0 \\
Total & 300 & $100 \%$ \\
\hline
\end{tabular}

Diseases: CMD, MHC, Ischemic and Rhythmic Heart Diseases, Mitral Disease, Mitroaortic Valvulopathy. Doppler echocardiography was not conducted in 174 patients.

they are not specific to this disease. The cardiac frequency was normal in $85.3 \%$. It can be explained by the mode of our patients' recruitment through out-patient 
Table 7. Distribution of patients according to the scan results.

\begin{tabular}{ccc}
\hline Scanographic pathologies & Frequency & Percentage (\%) \\
\hline Ischemic stroke & 8 & $2.7 \%$ \\
Brain tumor + HBP & 1 & $0.3 \%$ \\
Not done & 291 & $97.0 \%$ \\
Total & 300 & $100 \%$ \\
\hline
\end{tabular}

The vast majority of patients did not do the cerebral scanner, either 291.

Table 8. Distribution of patients according to the level of the blood pressure under treatment.

\begin{tabular}{ccc}
\hline Blood pressure under treatment & Frequency & Percentage (\%) \\
\hline Controlled & 206 & $68.7 \%$ \\
Not controlled & 94 & $31.3 \%$ \\
Total & 300 & $100 \%$ \\
\hline
\end{tabular}

department, most often reserved for patients who are relatively well. In regard to the number of hypertensive patients in the set, the proportion of $51.3 \%$ of left ventricular hypertrophy in the electrocardiogram was understandable. In opposition, only $13.3 \%$ of patients having done an echocardiography Doppler presented an anomaly in the examination. This reveals the interest of conducting such kind of examination with all the patients with anomalies in the electrocardiogram for a better labelling of the latter [2] [3]. Out of the 9 patients who underwent the cerebral scanner motivated by the existence of the signs of call, 8 of them had images compatible with an ischemic stroke. This pathology remains very frequent in the hypertensive population as attested by literature [3] [4]. In our set 42 patients, that is to say $14 \%$, presented an orthostatic hypotension and they were in majority hypertensive and under treatment (76\%). The high blood pressure was well controlled thanks to a medicinal treatment in $68.7 \%$. This high proportion of orthostatic hypotension reminds us of the urgent necessity to look for this manifestation in the hypertensive population under treatment. This kind of manifestation is responsible in the elderly population for fracture, brain injury and even death [3] [5] [6] [7] [8]. In the case of hypertensive patients with an orthostatic hypotension the control of blood pressure seemed to be more difficult to handle with a rate of $66.7 \%$ of non-control. That did not have any relationship with the number of antihypertensive people or the medicinal class used as sometimes it is found [8] [9]. Thus people noted in the set a more frequent association with monotherapy (47.6\%) without prejudging the class used. Biological examinations were normal in $52.4 \%$. Biological anomalies concerned creatininaemia, uricaemia and the rate of hemoglobin. This can be explained by the frequency of high blood pressure but also the quality of the diet responsible in many cases for deficiency-related anemia [9].

Limitations were essentially due to:

- The unaccomplishment of certain complementary examinations such as a 
complete lipid check-up;

- The absence of height gauge and weight scale did not permit to know the body mass index of patients (BMI);

- The weak size of the sample;

- Prolonged orthostatism made some elderly patients uncomfortable.

\section{Conclusion}

Hypertension is a frequent disease responsible for consultation in cardiology. The symptoms of Dieulafoy can be the signs of call. The conditions are sometimes frequent and should often be looked for before the signs of call and systematically. Orthostatic hypotension should be looked for even under monotherapy on balanced or non-balanced hypertension through treatment.

\section{Conflicts of Interest}

The authors declare no conflicts of interest regarding the publication of this paper.

\section{References}

[1] European Society of Hypertension-European Society of Cardiology. Guidelines Committee. (2013) 2013 ESH/ESC Guideline for the Management of Arterial Hypertension. Journal of Hypertension, 31, 1281-1357.

https://doi.org/10.1097/01.hjh.0000431740.32696.cc

[2] Beckett, N.S., Peters, R., Fletcher, A.E., Staessen, J.A., et al. (2008) Treatment of Hypertension in Patients 80 Years of Age or Older. The New England Journal of Medicine, 358, 1887-1898. https://doi.org/10.1056/NEJMoa0801369

[3] Federowski, A., Stavenow, L., Hedblad, B., Berglund, G., et al. (2010) Consequences of Orthostatic Blood Pressure Variability in Middle Aged Men (The Malmo Preventive Project). Journal of Hypertension, 28, 551-559. https://doi.org/10.1097/HJH.0b013e3283350e8c

[4] Asmar, R. (2002) Pression artérielle. Régulation et épidémiologie. Mesures et valeurs normales. Encycl MédChir (Editions Scientifiques et Médicales Elsevier SAS, Paris), Cardiologie, 11-301-A-10, 15 p.

[5] Bourdarias, J.P., Patrice, C. and Philippe, B. (1998) Pathologie cardiaque et vasculaire, hémostase et thrombose. In: Bletry, O., Hypotension Orthostatique, France, 490-494.

[6] Zipes, D.P. and Wellens, H.J. (1998) Sudden Cardiac Death. Circulation, 98, 2334-2351. https://doi.org/10.1161/01.CIR.98.21.2334

[7] Blétry, O. (1992) Aspects étiologiques des hypotensions orthostatiques. La Revue de Médecine Interne, 13, 430-436. https://doi.org/10.1016/S0248-8663(10)80024-4

[8] Senard, J.M. (2012) Hypotension Orthostatique: Physiopathologie, Diagnostic et Traitements. Cardiologie, 7, 1-18. https://doi.org/10.1016/S1166-4568(12)45138-5

[9] Schoenberger, J.A. (1991) Drug-Induced Orthostatic Hypotension. Drug Safety, 6, 402-407. https://doi.org/10.2165/00002018-199106060-00002 